Quebec Cooperative Study of

Friedreich's Ataxia

\title{
Nerve Conduction Studies and Electromyography in Friedreich's Ataxia
}

\author{
J. M. PEYRONNARD, L. LAPOINTE, J. P. BOUCHARD, A. LAMONTAGNE. \\ B. LEMIEUX, AND A. BARBEAU
}

SUMMARY: Twenty-six of 50 patients were investigated with nerve conduction studies and electromyography using a standard protocol and were compared to the findings in 50 normal control subjects. Almost all cases of typical Friedreich's ataxia had absent sensory action potentials (SAP) in the digital (92\%) or sural (96\%) nerves. The others had markedly decreased S.A.P's. In these same patients motor conduction

RÉSUMÉ: Chez 26 de nos 50 patients ataxiques, ane étude de la conduction nervease et de l'électromyogramme selon an protocole standard fiat effectuée en comparaison avec les résultats chez 50 contrôles normanx. Presque tous les cas d'ataxie de Friedreich "ypiques" se caracterisaient par whe absence complète des potentiels d'action sensitifs dans les nerfs digitau (92\%) ou sural (96\%). Les potentiels sensitifs étaient nettement diminués chez les au- velocities were either normal or only slightly decreased. In the second, atypical group of 9 patients, the motor condaction velocities were considerably decreased.

Because of the absence of sensory action potentials in Friedreich's ataxia, and that the absence nas noted in our very mild cases, it is proposed that this measure be used to facilitate early diagnosis.

tres. Par aillears, chez ces mêmes patients les vitesses de conduction motrices sont soit normales, soit à peine diminuées. Dans le second groupe de 9 patients "atypiques". Les conductions motrices sont fortement diminuées.

A cause de labolition totale presque constante des potentiels d'action sensitifs trìs tôt dans l'évolution de l'ataxie de Friedreich, nous proposons d'utiliser cette mesure pour faciliter le diagnostic précoce.
From the Hôpital Hôtel-Dieu de Montréal; The Hôpital de l'Enfant Jésus, Quebec City; The Centre Hospitalier de l'Université de Sherbrooke, and the Clinical Research Institute of Montreal.

Reprints requests for the complete supplement on Friedreich's ataxia to: Dr. André Barbeau. Clinical Research Institute of Montreal, 110 Pine Avenue west, Montreal, H2W IR7, Quebec. Canada.

\section{INTRODUCTION}

Nerve conduction studies represent an important diagnostic tool in patients with Friedreich's ataxia. They often reveal evidence of peripheral nerve involvement difficult to assess on a clinical basis. Abnormalities reported include absence or marked reduction in amplitude of sensory action potentials and mild slowing of motor nerve conductions.

This report gives the results of the electrophysiological studies performed on a group of 26 patients referred with the diagnosis of typical and atypical Friedreich's ataxia. The clinical features of these patients are reported in a previous paper.

\section{MATERIAL AND METHODS}

The age of onset of the 26 patients examined ranged from 4 to 15 years. At the time of the electrophysiological studies, the patients aged from 4 to 48 years and the duration of the disease varied from 1 to 40 years. All patients were tested in a warm room at a temperature of $23^{\circ} \mathrm{C}$ and lying on a couch, covered with a blanket. A three channel commercial model electromyograph DISA was used.

Sensory nerve action potentials (S.A.P.) were recorded with saddle surface electrodes from the superficial radial, median and ulnar nerves at the wrist after stimulation with ring electrodes (Dawson and Scott, 1949) of the thumb, index and little finger respectively. The sural nerve was stimulated antidromically at several points in the lower third of the posterior aspect of the leg and the responses were recorded with saddle surface electrodes applied at the ankle behind the lateral mal- 

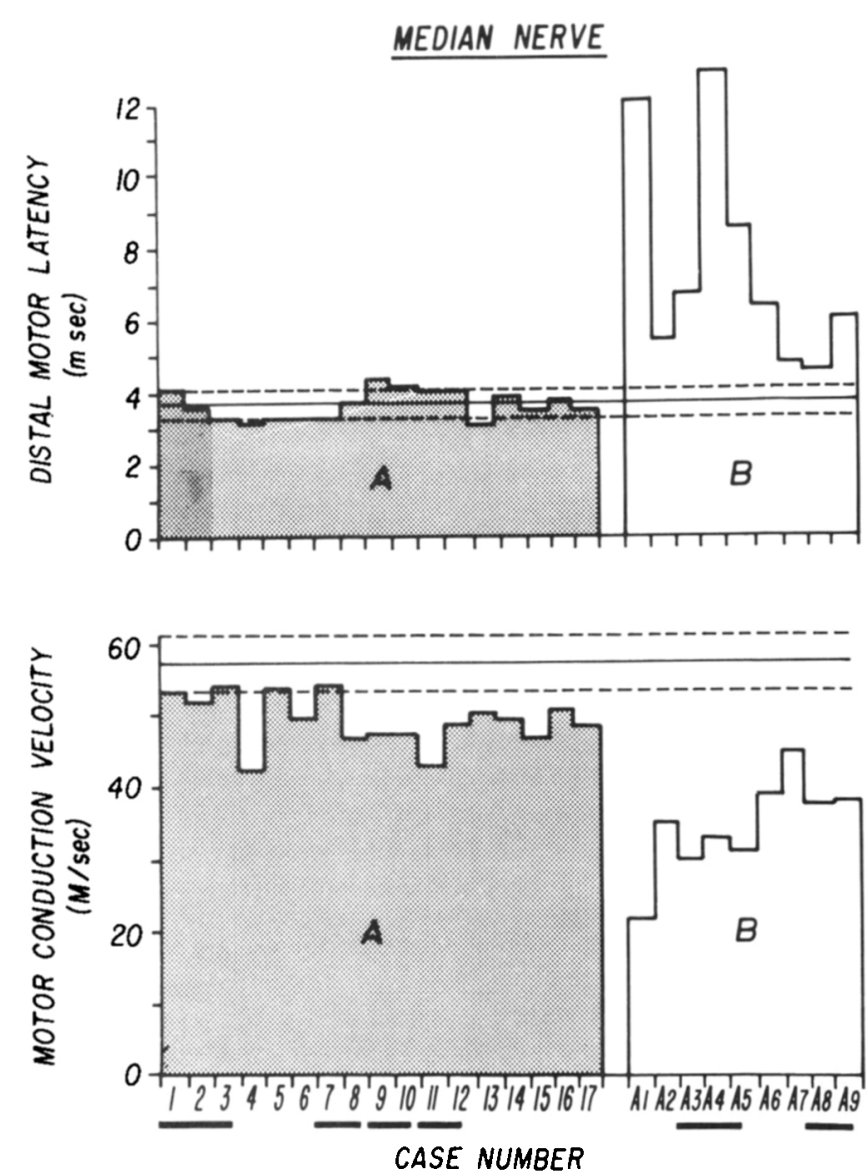

Figure I - Distal motor latencies and motor conduction velocities in the median nerve in two groups of ataxic patients: A: with typical Friedreich's ataxia:

B: with atypical recessive ataxia.

Underlined numhers indicate siblings. Horizontal lines represent normal meantstandard deviation.

leolus (Di Benetto, 1970; Dunn, 1973).

In all patients motor conduction velocity (M.C.V.) was measured in the median nerve and in 24 patients in the peroneal nerve. M.C.V. was also determined for the ulnar nerve in 14 patients and for the posterior tibial nerve in 12 cases. Muscle action potentials were registered with surface electrodes from the abductor pollicis brevis, adductor digiti minimi, extensor digitorum brevis and abductor hallucis brevis after supra maximal stimulation of the median, ulnar, peroneal and posterior tibial nerves respectively. Motor latencies were measured to the initial deflection of the potentials from the base line. M.C.V.'s were determined after stimulation at two different sites (wrist and elbow or ankle and knee levels).

Electromyogram (EMG) of the ex-
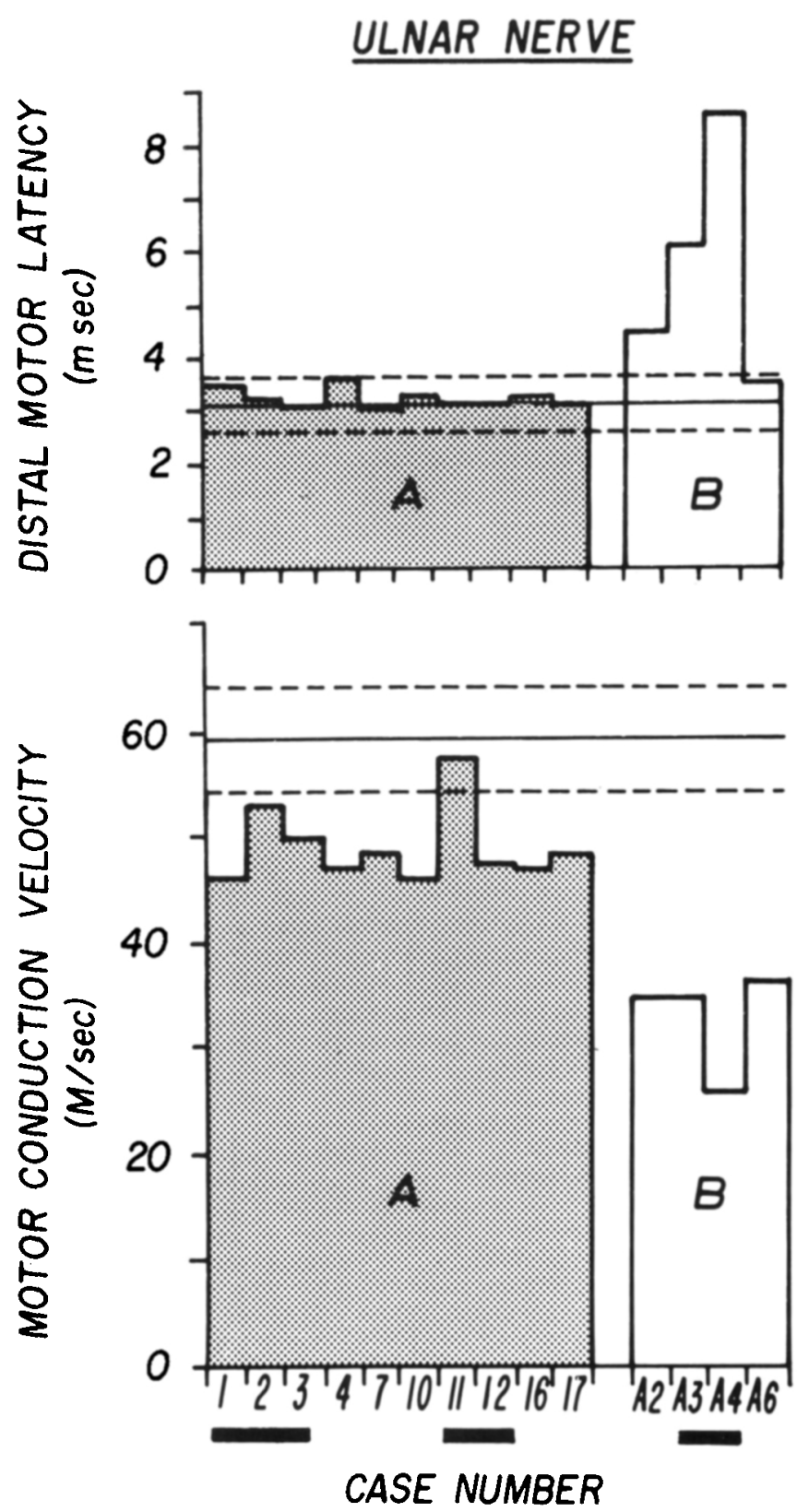

Figure 2 - Distal motor latencies and motor conduction velocities in the ulnar nerve. Same groups of patients as in Figure 1. Underlined numbers indicate siblings. Horizontal lines represent normal mean \pm standard deviation.

tensor digitorum brevis and tibialis anterior muscles was done using a concentric needle electrode. Several parameters were studied including the presence or absence of fibrillation potentials and of positive sharp waves, the presence or absence of polyphasic motor unit action potentials (M.U.A.P.'s) of prolonged duration and finally the pattern of recruitment of M.U.A.P.'s during maximal voluntary effort. Records obtained from 50 normal subjects (age 10 to 40 ) served as controls.

\section{RESULTS}

a) Sensory nerve conductions

Electrophysiological abnormalities in sensory fibers were present in all patients irrespective of age of onset or duration of the disease. Of 26 patients, 22 had no S.A.P. detectable at the wrist over the superficial radial, median or ulnar nerves after 


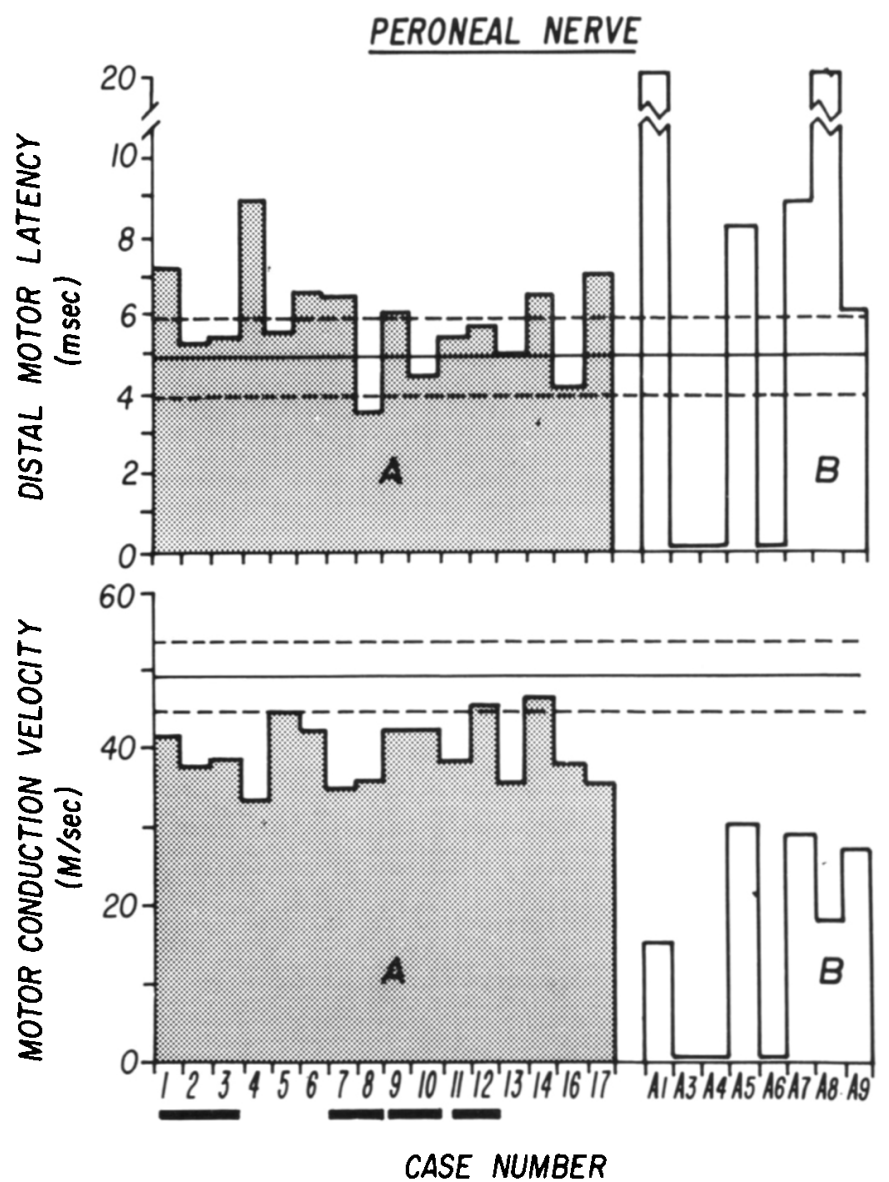

Figure 3 - Distal motor latencies and motor conduction velocities in the peroneal nerve. Same groups of patients as in Figure 1. Underlined numbers indicate siblings. Horizontal lines represent normal mean \pm standard deviation.

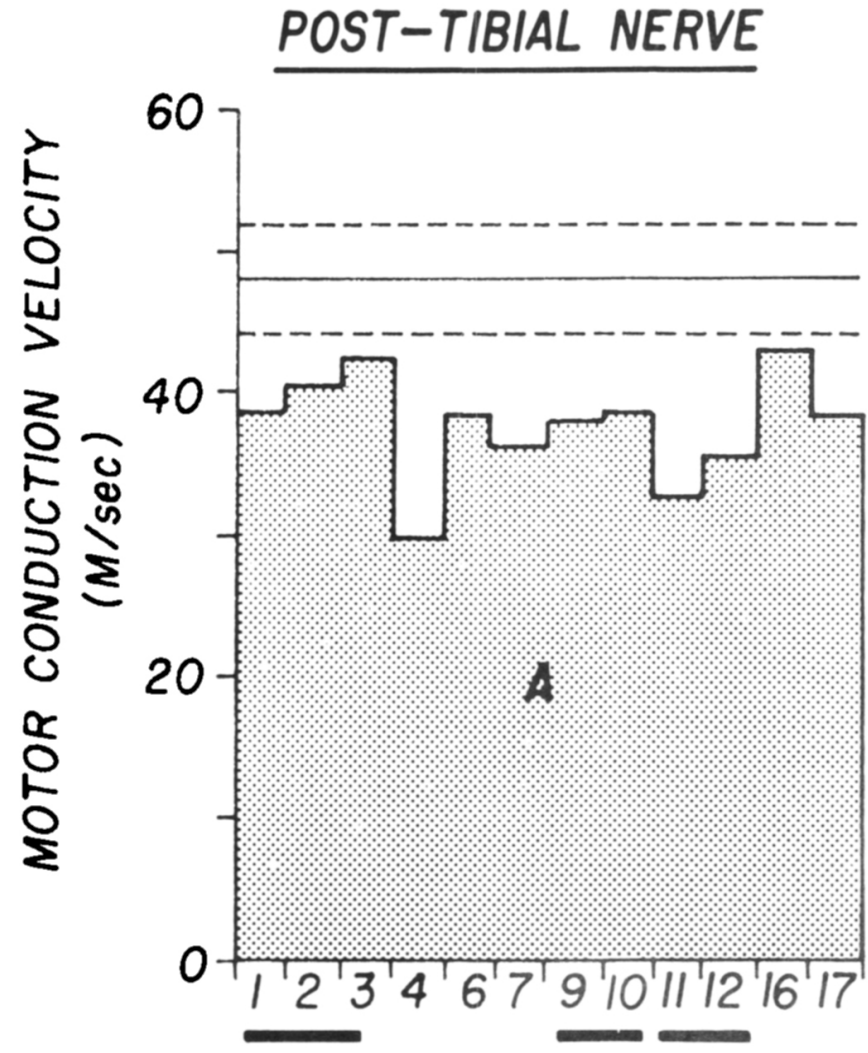

CASE NUMBER

Figure 4 - Motor conduction velocity in the posterior tibial nerve in typical Friedreich's ataxia. Underlined numbers indicate siblings. Horizontal lines represent normal mean \pm standard deviation. supramaximal stimulation of the digital nerves. In 4 patients, stimulation of the index finger evoked in the median nerve small S.A.P.'s $(3 \mu \mathrm{V}$ in amplitude or less - normal mean 12 $\mu \mathrm{V} \pm 3$ ) with low conduction velocities ranging between 35 and 46.9 $\mathrm{m} / \mathrm{sec}$. (Normal mean: $56.5 \mathrm{~m} / \mathrm{sec}$. $\pm 5.1)$.

In 25 patients, no response was obtained at the ankle on stimulating the sural nerve at several points in the leg. In one patient a nerve action potential was detected, but both its amplitude $(2 \mu \mathrm{V}$ - normal mean $10 \mu \mathrm{V}$ $\pm 4)$ and conduction velocity (31.9 $\mathrm{m} / \mathrm{sec}$ - normal mean $48.9 \pm 4.4$ ) were clearly diminished.

\section{b) Motor nerve conduction}

Values obtained for the median, ulnar, peroneal and posterior tibial nerves are shown in Figures 1, 2, 3 and 4 . Based on the degree of slow- ing of MCV's, two groups of patients could be identified. The first group (A) consisted of 17 patients, with borderline low MCV's both in upper and lower limbs. Conduction velocities of motor fibers averaged $46.7,49.1,36.4$ and $37.5 \mathrm{~meters} / \mathrm{sec}$. for the median, ulnar, peroneal and posterior tibial nerves, respectively. These are less than the normal mean values for these nerves $(57.6 \pm 3.9$, $59 \pm 5.3,49 \pm 4.6,47.8 \pm 4$, respectively). With a few exceptions, distal motor latencies were within normal limits. Clinically all of them presented the typical criteria of the disease (Group Ia). The second group (B) of 9 patients was characterized by a marked slowing of MCV's with average values of $34.5,33.1$ and 23.5 meters $/ \mathrm{sec}$. for the median, ulnar and peroneal nerves respectively. In three patients, no response was obtained on stimulating the right and left peroneal nerves at the ankle or at the knee. Finally. in most instances distal motor latencies were prolonged. All the patients in this group belonged to atypical (Group II) cases. In neither group was there a correlation between the degree of slowing of MCV and the age of onset or the duration of the disease (Figure $5)$.

\section{c) Electromyographic studies}

EMG findings in the extensor digitorum brevis and tibialis anterior muscles are summarized in Table 1. It can be seen that fibrillation potentials and/or positive sharp waves were infrequent in patients of Group A or B. They were present in only $16 \%$ of the tested muscles.

Polyphasic M.U.A.P.'s of prolonged duration were observed in $34 \%$ of the muscles in which a voluntary activity could be elicited. Loss 


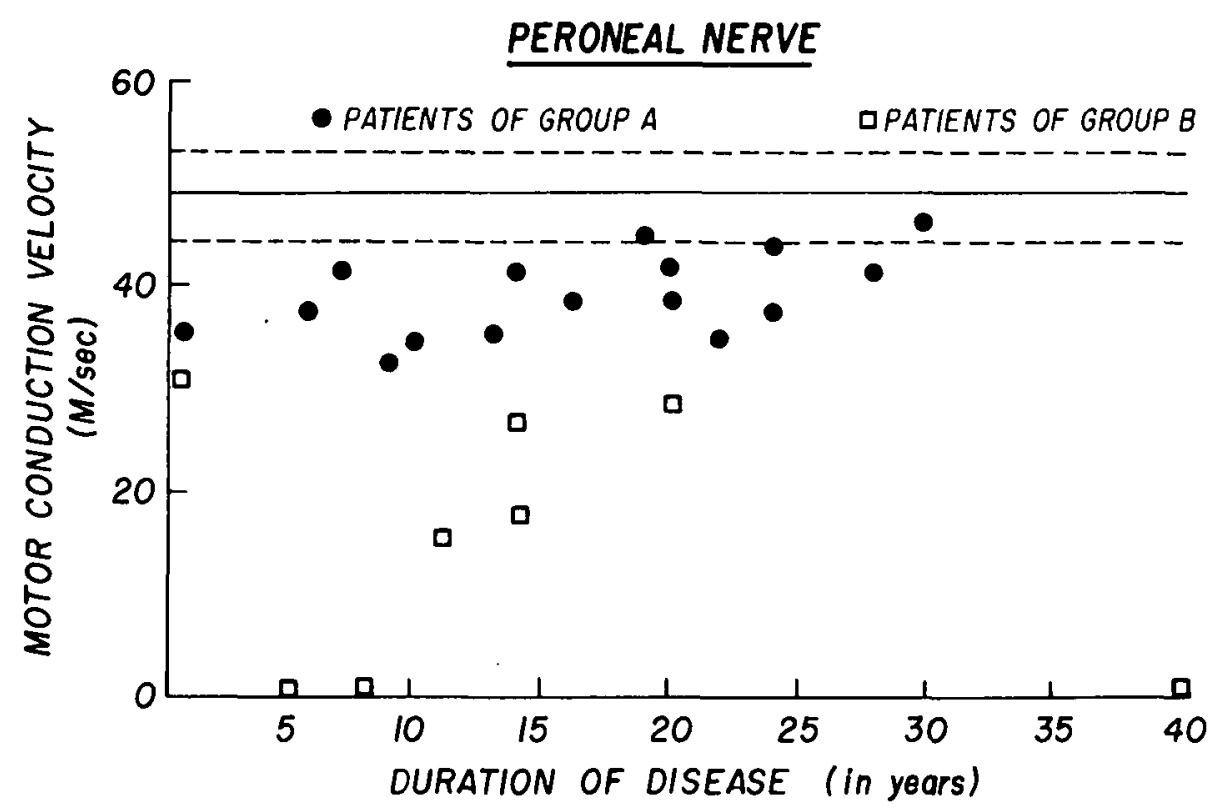

Figure 5 - Motor conduction velocities in the peroneal nerve as a function of the duration of disease in the 2 groups of patients described in Figure 1. Horizontal lines represent normal mean \pm standard deviation. of suprasegmental influences could partly explain the total inability of a few patients to activate voluntarily M.U.A.P.'s. The same explanation could hold for the diminution of the interference pattern during maximal voluntary effort which was noted in most of the other patients.

\section{DISCUSSION}

As reported previously in Friedreich's ataxia (Preswick, 1968; Dyck and Lambert, 1968; McLeod, 1971; Oh and Hasley, 1973; Fiaschi et al., 1976), impairment of sensory conduction was the most striking and common abnormality found in this series of 26 patients with typical and atypical features of the disease. Digital nerve S.A.P.'s and sural nerve action potentials were absent in $92 \%$ and $96 \%$ of the cases respectively, whereas the remainder of the patients had abnormally low amplitude potentials with slow conduction velocities.

Such findings are in keeping with the pathological observations made in Friedreich's ataxia, which show a selective degeneration of the large neurons in the posterior root ganglia with a disappearance of large myelinated fibers in peripheral sensory nerves (Hughes et al., 1968; McLeod, 1971). In view of the fact that no S.A.P.'s could be recorded in a 8 year-old girl whose mild clinical symptoms had begun a year prior to examination, it is likely that the degenerative phenomena start early in life. Therefore, studies of S.A.P.'s may represent a useful diagnostic test for early detection of affected children in families with a positive history of Friedreich's ataxia.

In a group of 17 patients presenting the typical features of the dis- ease, M.C.V.'s were only slightly diminished irrespective of the duration of illness. On the whole, the values were similar to those reported previously (Preswick, 1968; Dyck and Lambert, 1968; McLeod, 1971; Oh and Hasley, 1973; Salisachs et al., 1975; Fiaschi et al., 1976). This mild slowing of motor conduction is in agreement with the concept that patients with Friedreich's ataxia have a chronic slowly progressive motor neuropathy of the dying-back type producing axonal degeneration of large myelinated fibers. The slow rate of progression of the disease may explain (Salisachs et al., 1975) the subtleness of neuropathic changes observed on EMG examination of lower limbs muscles.

A second group of 9 patients had markedly slow MCV's and the severity of the abnormalities was of the same magnitude in brothers and sisters of 2 families examined. It is likely that these patients represent a separate entity whether they have the Roussy-Levy syndrome (RLS) or the Charcot-Marie-Tooth disease (CMTD). RLS has been distinguished from Friedreich's ataxia on the basis of several criteria. The mode of inheritance is different, being autosomal recessive in Friedreich's ataxia and usually autosomal dominant in the RLS (Yudell et al., 1965; Oelschlager et al., 1971). Clinically, patients with
TABLE 1

EMG Findings in Ataxia

\begin{tabular}{|c|c|c|c|c|c|c|c|}
\hline & \multicolumn{2}{|c|}{$\begin{array}{l}\text { FIBRILLATIONS } \\
\text { AND/OR } \\
\text { POSITIVE } \\
\text { SHARP WAVES } \\
\end{array}$} & \multicolumn{2}{|c|}{$\begin{array}{l}\text { POLYPHASIC } \\
\text { M.U.A.P.'S } \\
\text { OF PROLONGED } \\
\text { DURATION } \\
\end{array}$} & \multicolumn{3}{|c|}{$\begin{array}{c}\text { PATTERN OF RECRUIT- } \\
\text { MENT OF M.U.A.P. DURING } \\
\text { MAXIMAL } \\
\text { VOLUNTARY EFFORT } \\
\end{array}$} \\
\hline & Absent & Present & Absent & Present & Normal & Decreased & $\begin{array}{l}\text { No } \\
\text { M.U.A.P. }\end{array}$ \\
\hline GROUP A & & & & & & & \\
\hline $\begin{array}{l}\text { Ext. Digit. Brev. } \\
(\mathrm{N}: 14)\end{array}$ & 12 & 2 & 8 & 3 & 2 & 9 & 3 \\
\hline $\begin{array}{l}\text { Tib. Ant. } \\
\text { (N:13) }\end{array}$ & 10 & 3 & 10 & 1 & 3 & 8 & 2 \\
\hline \multicolumn{8}{|l|}{ GROUP B } \\
\hline $\begin{array}{l}\text { Ext. Digit. Brev. } \\
(N: 7)\end{array}$ & 6 & 1 & 2 & 3 & & 5 & 2 \\
\hline $\begin{array}{l}\text { Tib. Ant. } \\
\text { (N:9) }\end{array}$ & 8 & 1 & 3 & 5 & 1 & 7 & 1 \\
\hline
\end{tabular}


the RLS present with clumsy gait, dysequilibrium while standing, pes cavus, areflexia, clumsiness and slight atrophy of the hands and tremor. The original papers (RoussyLevy, 1926, 1932, 1934) mentioned certain distinct features such as the early onset of gait disturbance, the slow progression of disability and the absence of cerebellar or corticospinal tract involvement. Little has been added to this description with the exception that impairment of position and vibratory sense has been noted in many of these patients (Spillane, 1940; Yudell et al., 1965; Oelschager et al., 1971) whereas a few of them may have Babinski's sign or a severe amyotrophy, the latter being a late feature of the disease (Lapresle, 1956). A constant finding in the RLS has been a marked slowing of MCV's (Oeschlager, 1971; Yudell et al., 1965) comparable to that seen in patients with CMTD. The similarity of the mode of inheritance as well as the clinical picture led Yudell et al. (1965) to the conclusion that the RLS was a form of CMTD associated with essential tremor. As nerve hypertrophy and onion-bulb formations have been observed in both conditions, they are now classified as dominantly inherited hypertrophic neuropathy Type I (Dyck, 1975). It is obvious that in our series a definite classification of this second group of patient must await the result of histological examination of sural nerve biopsies.

\section{ACKNOWLEDGMENTS}

The studies reported in this paper were partially supported by L'Association Canadienne de l'Ataxie de Friedreich. by La Fondation Jeanne-Mance and by the Medical Research Council of Canada.

\section{REFERENCES}

DAWSON, G. D.. and SCOTT. J. W. (1949). The recording of nerve action potentials through the skin in man. J. Neurol. Neurosurg. Psychiat., 12, 259-267.

DI BENETTO, M. (1970). Sensory nerve conduction in lower extremities. Arch Phys. Med. Rehab., 51, 253-258.

DYCK, P. J., and LAMBERT. E. H. (1968). Lower motor and primary sensory neuron diseases with peroneal muscular atrophy. II. Neurologic, genetic, and electrophysiologic findings in various neuronal degenerations. Arch. Neurol., 18, 619-625.

DYCK. P. J. (1975). Inherited neutonal degeneration and atrophy of peripheral motor, sensory and autonomic neurons. In: Peripheral Neuropathy. W. B. Saunders Co., Vol. II, (DYCK. P. J.. Thomas, P. K.. and Lambert. E. H.. eds.), pp. 825-867.

DUNN, H. G. (1973). Nerve conduction studies in children with Friedreich"s ataxia and ataxia - telangiectasia. Develop. Med. Child Neur. 15, 324-337.

FIASCHI, A.. FERRARI, G.. DE GRANDIS, D., and TOMELLERI, G. (1976). Aspetti electromiografici ed istologici in corso di malattia di Friedreich. Acta Neurologica (Napoli), 31, 162-169.

HUGHES, T. J.. BROWNELL. B., and HEWER, R. L. (1968). The peripheral sensory pathway in Friedreich's ataxia. An examination by light and electronmicroscopsy of the posterior nerves roots, sensory nerves in cases of Friedreich's ataxia. Brain, 91. 803-818.
LAPRESLE. J. (1956). Contribution à l'étude de la dystasie aréflexique héréditaire: Etat actuel des sept cas princeps de Roussy et de Mlle Lévy. trente ans après la premiere publication de ces auteurs. Sem. Hop. Paris, 32. 2473-2482.

McLEOD. J. G. (1971). An electrophysiological and pathological study of peripheral nerves in Friedreich's ataxia. J. Neurol. Sci.. 12. 333-349.

OELSCHI_AGER. R., WHITE. H. R., and SCHIMKE, R. N. (197I). Roussy-lévy syndrome: Report of a kindred and discussion of the nosology. Acta Neurol. Scandinav.. 47. 80-90.

OH. S. J., and HASLEY J.H. (1973). Abnormality in nerve potentials in Friedreich"s ataxia. Neurol. 23, 52-54.

PRESWICH. G. (1968). The neuropathy of Friedreich's ataxia Proc. Aus. Ass. Neurologists. 5, 69-71.

ROUSSY, G., and LEVY, G. (1962). Sept cas d'une maladie familiale particulière: Troubles de la marche, pieds bots. et aréflexie tendineuse généralisée avec accessoircment légère maladresse des mains. Rev. Neurol., 427-450.

ROUSSY. G.. and LEVY. G. (1932). L.a dystasie aréflexique héreditaire. Presse Méd., 2. 1733-1736.

ROUSSY. G., and Levy. G. (1934). A propos de la dystasie aréflexique héréditaire. Contribution a l'étude de la génèse des maladies familiales et de leur parente entre elles. Rev. Neurol.. 2. 763.773.

SALISACHS, P.. CODINA. M.. and PRADAS. J. (1975). Motor conduction velocity in patients witt. Friedreich`s ataxia. J. Neurol. Sci., 24, 33 -337.

SPILLANE. J. D. (19.10). Familial pes civus and absent tendon-jerk: Its relationship with Friedreich's disease and peroneal muscular atrophy. Brain. 63, 275-290.

YUDELL. A.. DYCK, P, J.. and I.AMBERT, E. H. (1965). A kindship with the Roussy-Lévy syndrome. A clinical and electrophysiologic study. Arch. Neurol. 13. 432-440. 